\title{
Design and Analysis of Structural Element Mounting Plate for Section-IV of an Aerospace Vehicle under Rolling Condition
}

\author{
Chunchu Sravanthi ${ }^{1}$, Pratibha Dharmavarapu ${ }^{2}$ \\ ${ }^{I}$ (Department of Mechanical Engineering, Anurag Group of Institutions, Telangana, India) \\ ${ }^{2}$ (Department of Mechanical Engineering, Anurag Group of Institutions, Telangana, India)
}

\begin{abstract}
Aerospace vehicle is divided into number of sections. Section-I is nosecone, Section-II contains payload, Section-III contains Navigation \& Guidance systems \& Section-IV contains Avionics Batteries and other Aerospace electronics sub-systems. The Section-IV is of 500mm length and $420 \mathrm{~mm}$ diameter with $5 \mathrm{~mm}$ thick airframe accommodating control batteries (thermal batteries 3 Nos) and Avionics battery (thermal, 1 No), Battery Voltage Monitoring Circuit (BVMC) package, Contractor Box and an Interface Mounting Plate. Control Batteries and Avionics Battery are mounted on a plate using clamps and brackets and other electronic units like $B V M C$ and contractor Box are mounted using fasteners. The mounting plate assembly is then mounted on four brackets of the air-frame of Section-IV of an Aerospace vehicle. The modeling of structural element Mounting Plate is done using CAD software, ProEngineer Wildfire 5.0 and Analysis is carried out under rolling condition using Analysis CAE Software, ANSYS 12.0. The results are interpreted with various loads and matched with theoretical calculations. The Factor of Safety of structural element is found within the limits and hence the overall design is found to be safe for Aerospace application.
\end{abstract}

Keywords: Aerospace Vehicle, Analysis, Battery, Mounting Plate, Section-IV

\section{Introduction}

In flight, any aircraft will rotate about its center of gravity, a point which is the average location of the mass of the aircraft. We can define a three dimensional coordinate system through the center of gravity with each axis of this coordinate system perpendicular to the other two axes. We can then define the orientation of the aircraft by the amount of rotation of the parts of the aircraft along these principal axes. The roll axis lies along the aircraft centerline. A roll motion is an up and down movement of the wings of the aircraft.

The rolling motion is being caused by the deflection of the ailerons of this aircraft. The aileron is a hinged section at the rear of each wing. The ailerons work in opposition; when the right aileron goes up, the left aileron goes down. As described on the shape effects slide, changing the angle of deflection at the rear of an airfoil will change the amount of lift generated by the foil. With greater downward deflection, the lift will increase in the upward direction; with greater upward deflection, the lift will decrease in the upward direction. Since the ailerons work in pairs, the lift on one wing increases as the lift on the opposite wing decreases. Because the forces are not equal, there is a net twist, or torque about the center of gravity and the aircraft rotates about the roll axis. The pilot can use this ability to bank the aircraft which causes the airplane to turn.

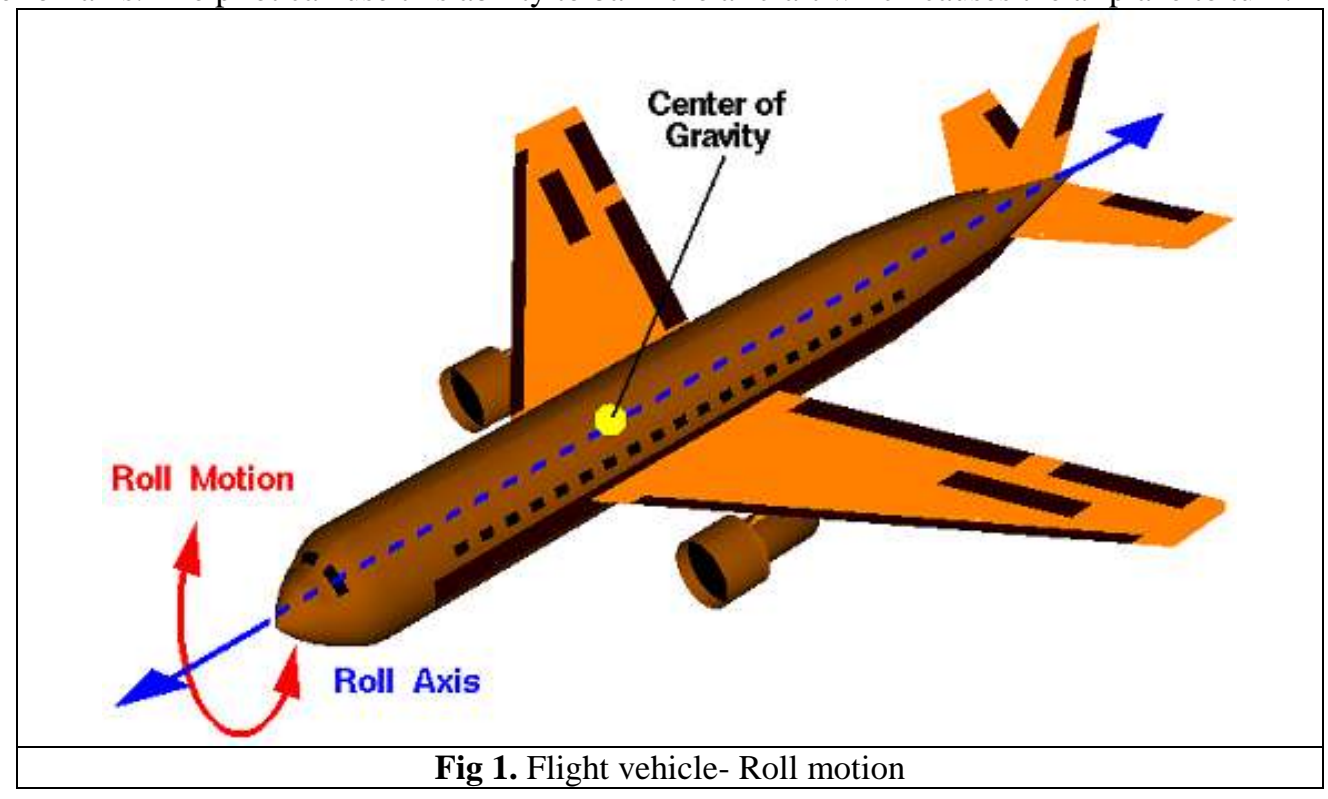


On this page we have demonstrated an aircraft roll induced by movement of the ailerons, but there are other ways to produce a rolling motion on an aircraft. The Wright brothers used a method called wing warping. Their wings were wired together in such a way that the outer panels of each wing could be twisted relative to the inner panel. The twisting changed the local angle of attack of sections of the wing which changed the lift being generated by that section. Unequal forces on the wings caused the aircraft to roll. Many modern airliners use a spoiler to roll the aircraft. A spoiler is a plate that is raised between the leading and trailing edges of the wing. The spoiler effectively changes the shape of the airfoil, disrupts the flow over the wing, and causes a section of the wing to decrease its lift. This produces an unbalanced force with the other wing, which causes the roll. Airliners use spoilers because spoilers can react more quickly than ailer

\section{Modelling}

The Section-IV of Aerospace vehicle houses sub systems meant for Control Actuation. This section is of 500 $\mathrm{mm}$ length and $420 \mathrm{~mm}$ diameter with $5 \mathrm{~mm}$ thick Airframe. These sub systems are mounted on mounting plate. This assembly is assembled inside the section (airframe) using four brackets. The mounting Plate carries Subsystems like

- Control Batteries (Thermal) for Control Actuation System (3 No's)

- Avionics Battery (Thermal)

- BVMC-Battery Voltage Monitoring Circuit

- Contactor Box.

The total mass of the Assembly resting over the four Brackets is around $17.7 \mathrm{Kg}$. The weight of the Sub system under the longitudinal acceleration levels of $27.5 \mathrm{~g}$ and lateral acceleration levels of $8 \mathrm{~g}$ imparts external loading in the form of forces and moments over the structural elements like Mounting Plate, Brackets and Fasteners. These elements are designed and analyzed to withstand the acceleration loads.
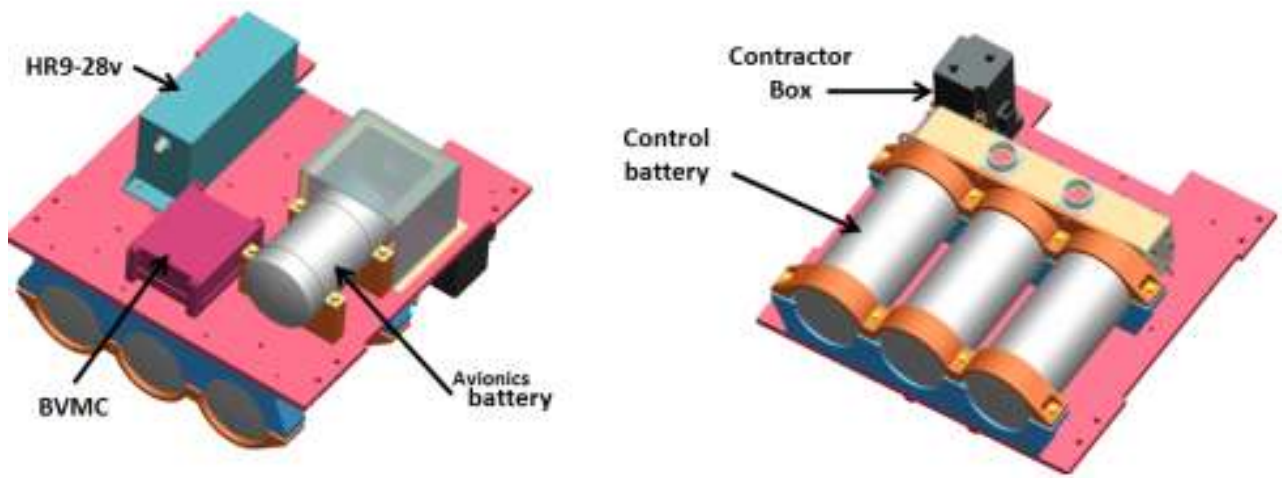

Fig 2. Section-IV airframe with packages mounted on plate

\section{Mounting Plate}

The mounting plate is modeled in Pro Engineer CAD software as shown in Figure 3.

Aluminium Alloy 24345 (WP condition) material is used for Plate and its properties are given below.

Plate (IS: 736) : UTS: 405 MPa, PS: $310 \mathrm{MPa}, \%$ e: 7

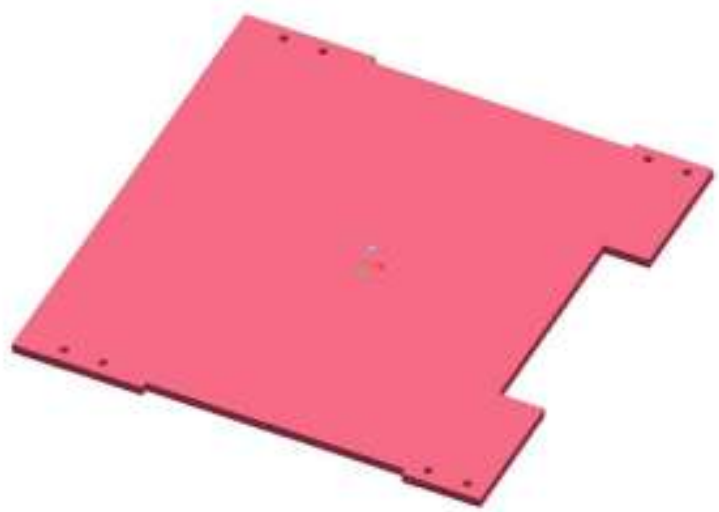

Fig 3. Mounting Plate 


\subsection{CONTROL BATTERY (THERMAL) WITH CLAMPS AND BRACKETS}

Control Battery (Thermal) is used for supplying power to the control actuation system. The Control Batteries (Thermal) are of Ø80x190 length. Three number of batteries are mounted in series on bottom mounting brackets and clamped using M5 screws (8 No's) using top clamps. Bakelite Hylam Grade F2 IS:2036 material has been used for mounting the batteries for insulation.

\subsection{AVIONICS BATTERY(THERMAL) MOUNTED ON CLAMPS AND BRACKETS}

Avionics Battery (Thermal) is used for supplying power to the electronic packages mounted in Sections II to IV. The Battery is of Ø80x145 length. The battery is mounted on mounting brackets and clamped using M5 screws (8 No's) using top clamps. Bakelite Hylam Grade F2 IS:2036 material has been for mounting the batteries for insulation.

\subsection{BVMC (BATTERY VOLTAGE MONITORING CIRCUIT) PACKAGE}

Battery Voltage Monitoring Circuit Package is used for monitoring of voltages of various Batteries mounted in Section-IV. The Output Voltages of all batteries are monitored and converted into Digital form and send to Onboard Computer for Telemetry Applications.

\subsection{HR5-9V BATTERY}

HR5-9V Battery is used for powering-up the Autonomous Aero-space Vehicle Destruction System (AVDS). The Battery provides 5 Amps at 9V Volts to the necessary External AVDS.

\subsection{CONTACTOR BOX}

The Contractor Box is used for activating the Control batteries for Actuating Purpose. The Control Batteries ( 3 Nos) are connected in series to provide a actuating voltage of $150 \mathrm{~V}$. The Contractor Box receives command from On-board Computers to enable the Actuating Voltage to Actuating Systems.

\section{Analysis of Plate}

The Plate is subjected to the external loads and moments due to loading are caused by the packages mounted on the plate during Roll (CW \& $\mathrm{CCW}$ ) condition. Analysis is carried out in this condition and the results are depicted and tabulated. The mounting plate having sub system mounting holes is imported to ANSYS software. The Plate is modeled using eight noded Shell elements (Shell 281) with a uniform thickness of $8 \mathrm{~mm}$ with 4983 elements. The nodes of holes plate at the lugs to be interfaced with Airframe are arrested in all degrees of freedom.

\section{Loading In Longitudinal Direction (Roll)}

During Rolling (CW \& CCW) condition, moments are calculated and applied on the plate generated by the packages mounted on the plate about X-axis. Analysis has been carried out for Roll-CW condition and the same is applicable for the Roll-CCW condition. Deflections and stresses are obtained and the plots are depicted from Figure 6.13 to Figure 6.19.

Weight of Thermal Battery (Control) with brackets

Force caused by Battery in $27.5 \mathrm{~g}$ state $=8.98 * 9.81 * 27.5$

Moment caused by Battery when Force acts through its CG $=2422.6 x 45$

Moment transferred via each fastener $=109017 / 8$

Weight of Thermal Battery (Avionics) with brackets

Force caused by Battery in $27.5 \mathrm{~g}$ state $=2.26 * 9.81 * 27.5$

Moment caused by Battery when Force acts through its CG $=609.7$ x 45

Moment transferred via each fastener $=27436.5 / 4$

$$
\begin{aligned}
= & 8.98 \mathrm{Kg} \\
= & 2422.6 \mathrm{~N} \\
= & 109017 \mathrm{~N}-\mathrm{mm} \\
= & 13627.13 \mathrm{~N}-\mathrm{mm} \\
= & 2.26 \mathrm{Kg} \\
= & 609.7 \mathrm{~N} \\
= & 27436.5 \mathrm{~N}-\mathrm{mm} \\
= & 6859.13 \mathrm{~N}-\mathrm{mm} \\
& =1.95 \mathrm{Kg} \\
& =518 \mathrm{~N} \\
& =22274 \mathrm{~N}-\mathrm{mm} \\
& =5568.5 \mathrm{~N}-\mathrm{mm} \\
& =0.7 \mathrm{Kg} \\
= & 188.8 \mathrm{~N} \\
= & 4154.54 \mathrm{~N}-\mathrm{mm} \\
= & 1038.6 \mathrm{~N}-\mathrm{mm} \\
= & 0.76 \mathrm{Kg} \\
= & 205 \mathrm{~N} \\
= & 9226.3 \mathrm{~N}-\mathrm{mm} \\
= & 4613.2 \mathrm{~N}-\mathrm{mm}
\end{aligned}
$$$$
\begin{aligned}
& \text { Moment caused by Battery when Force acts thro } \\
& \text { Moment transferred via each fastener }=22274 / 4
\end{aligned}
$$

Weight of BVMC package

Force caused by Battery in $27.5 \mathrm{~g}$ state $=0.7 * 9.81 * 27.5$

Moment caused by Battery when Force acts through its CG $=188.8$ x 22

Moment transferred via each fastener $=4154.54 / 4$

Weight of Contactor package

Force caused by Battery in $27.5 \mathrm{~g}$ state $=0.76 * 9.81 * 27.5$

Moment transferred via each fastener $=9226.3 / 2$ 


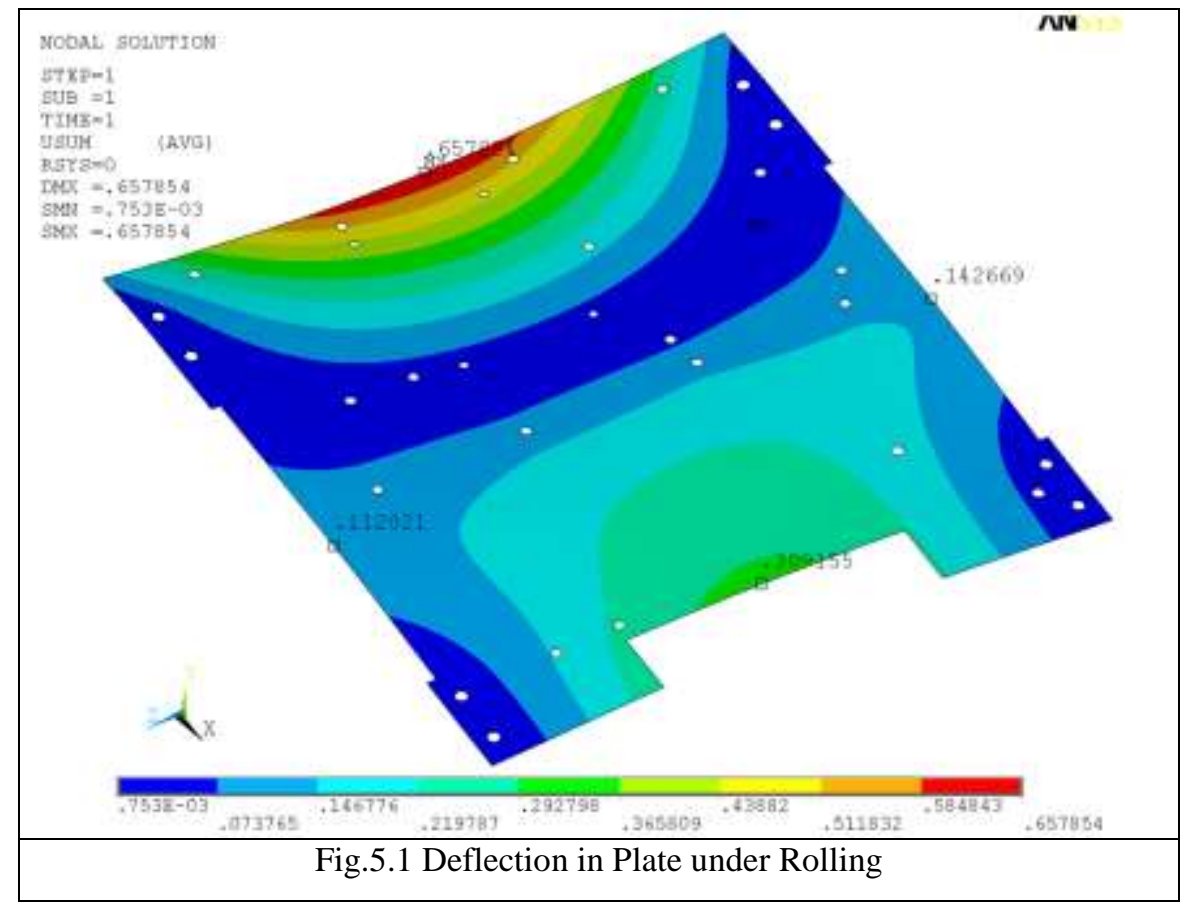

From the Fig.5.1, The maximum deflection obtained for Plate is $0.66 \mathrm{~mm}$.

\section{Theoretical Comparison}

Assuming the loading on the plate to be a Rectangular plate with edges built in condition with load at the center (Theory of Plate \& Shells-S. Timoshenko, Woinowsky-Krieger, Page No. 206, Table 37), the load of all the packages including plate is $17 \mathrm{Kg}$.

Length of the plate, $b=400 \mathrm{~mm}$

Width of the plate, $a=345 \mathrm{~mm}$,

$\mathrm{b} / \mathrm{a}=1.2$, Deflection of plate $=\alpha \frac{\mathrm{ru}}{\mathrm{n}}$

Where $\alpha=0.00647$, (based on b/a ratio)

$\mathrm{P}=$ Load on the plate $=17 \mathrm{Kg}$

$=17 * 9.81 * 8=1334.16 \mathrm{~N}$

$\mathrm{a}=345 \mathrm{~mm}$

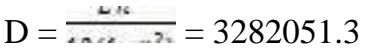

Where $\mathrm{E}=0.7 \mathrm{e} 5, \mathrm{~h}=$ Thickness of the plate $=8 \mathrm{~mm}, \mu=0.3 \mathrm{~mm}$

substituting the above values, Deflection of plate $=0.3 \mathrm{~mm}$

The deflection obtained by FE result is less than theoretical comparison. The calculation is used for a qualitative assessment.

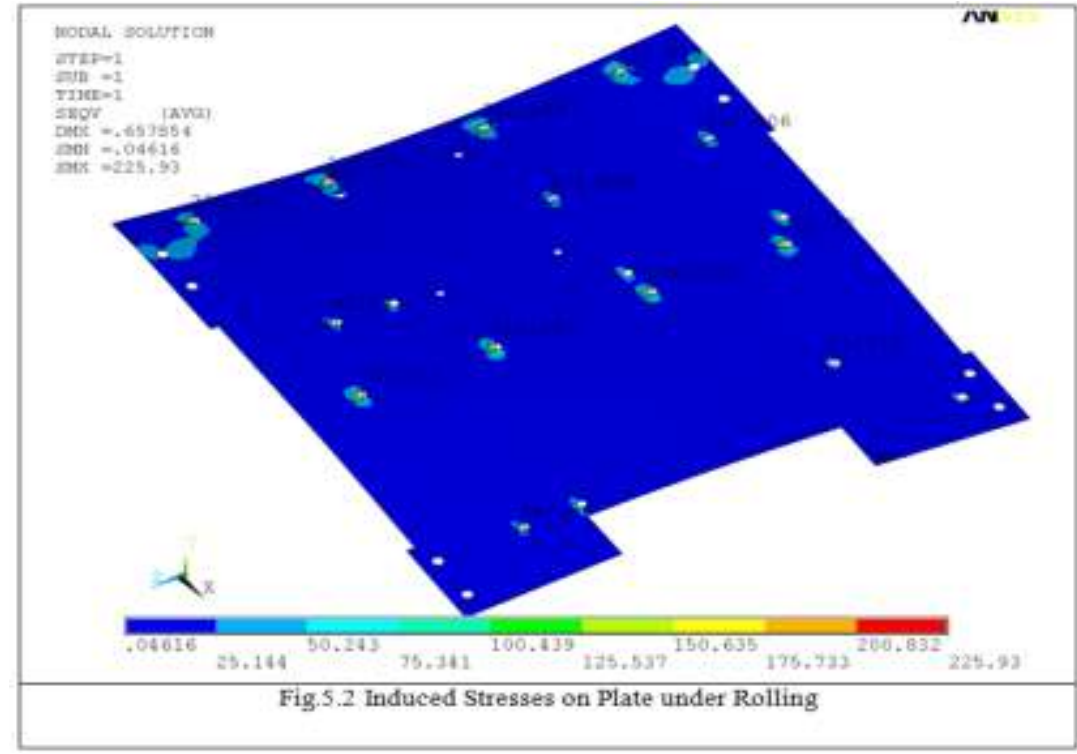


From Fig.5.2 Maximum induced Stress in the Plate $=25 \mathrm{MPa}$

FOS $=310 / 25=12.4$

\section{VII.Conclusion}

The permissible Factor of Safety for design of Aerospace vehicles structures is 1.5

$>$ Maximum deflection obtained for Mounting Plate under rolling condition is $0.66 \mathrm{~mm}$ which is within the limits.

$>$ Maximum Stress obtained for Mounting Plate under rolling condition is 25MPa which gives FOS equal to 12.4 which is greater than 1.5. Hence the design of Mounting Plate is safe.

\section{Acknowledgement}

We are thankful to Mr. Umakanth, Senior Scientist of Research Centre Imarat, DRDO, Hyderabad for his valuable inputs for realization of above and completing the project tasks at our institute. We are also sincerely thankful to Management of Anurag Group of Institutions for allowing us to do the project.

\section{References}

[1]. MIL-HDBK-5B, Metallik Material and Elements for Aerospace Vehicle Structures, Department of Defence (DoD), Washington DC

[2]. Theory of Plate \& Shells-THIMOSHENKO

[3]. Finite Element Analysis by CS KrishnaMurhty

[4]. Introduction to Finite Elements in Engineering Practice by “ Tirupati R. Chandrapatla and Ashok D. Belugundu”

[5]. Theory of Machines by SS Rattan.

[6]. Strength of Materials-B.C. Punmia 